\title{
PERANCANGAN RUMAH SUSUN DI PONDOK KELAPA JAKARTA TIMUR DENGAN PENDEKATAN ARSITEKTUR PERILAKU
}

\author{
Rizki Ramadhan ${ }^{1}$, Karya Widyawati ${ }^{2}$, Wiyoga Triharto ${ }^{3}$ \\ ${ }^{1}$ Universitas Indraprasta PGRI, Program Studi Arsitektur \\ rizkikiloy96@email.com \\ ${ }^{2}$ Universitas Indraprasta PGRI, Program Studi Arsitektur \\ widyawatik@yahoo.co.id \\ ${ }^{3}$ Universitas Indraprasta PGRI, Program Studi Arsitektur \\ wiyogatriharto@yahoo.com
}

\begin{abstract}
The purpose of the Flats is to design a beautiful and comfortable Flats concept with a view to the community living along the river. This design is planned to be relocated by the Government, with the construction of a unit designed to obtain optimal lighting and air circulation making this apartment housing not only comfortable but also healthy. In addition there are facilities and supporting facilities for people who live in the Pondok Kelapa Flats, East Jakarta. The design uses the Behavioral Architecture Approach Concept, and uses the behavior mapping methodology with the process of collecting data on an object and observing the object as data that will be implemented to design an apartment in Pondok Kelapa, East Jakarta.
\end{abstract}

Keywords: Design, Flats, Behavioral Architecture

\begin{abstract}
Abstrak. Tujuan Perancangan Rumah Susun adalah untuk mendesain hunian berkonsep Rumah Susun yang asri dan nyaman dikhususkan untuk masyarakat yang tinggal dibantaran sungai. Perancangan ini rencananya akan di relokasi oleh Pemerintah, dengan pembangunan unit yang didesain mendapatkan pencahayaan dan sirkulasi udara yang optimal menjadikan hunian rumah susun ini bukan hanya nyaman namun juga sehat. Selain itu ada fasilitas dan sarana pendukung untuk masyarakat yang tinggal di kawasan Rumah Susun Pondok Kelapa, Jakarta Timur. Perancangan menggunakan Konsep Pendekatan Arsitektur Perilaku, dan menggunakan metodelogi behavior mapping dengan proses pengumpulan data pada sebuah objek dan mengamati objek tersebut sebagai data-data yang akan di implementasikan untuk merancang sebuah rumah susun di Pondok Kelapa Jakarta Timur.
\end{abstract}

Kata Kunci : Perancangan, Rumah susun, Arsitektur Prilaku

\section{PENDAHULUAN}

Pemerintah mengedepankan Kawasan bantaran sungai. Sungai hanya menjadi halaman belakang kota, terabaikan, dan jarang tersentuh. Akibatnya pemukiman kumuh tumbuh berkembang secara liar di pinggir sungai. Penduduknya merupakan kaum pendatang ataupun penduduk asli kota yang tak mampu membeli rumah secara layak. Pemukiman kumuh pada umumnya sangat tidak tertata, sanitasinya buruk, dan akses yang ala kadarnya. Keberadaan lingkungan kawasan permukiman kumuh pun membawa permasalahan baru, seperti perkembangan fisik kota yang tidak baik, memberikan efek visual yang jelek, tingkat kesehatan masyarakat yang semakin rendah sebagai akibat dari kondisi permukiman yang tidak sesuai dengan standar kesehatan dan memberikan dampak sosial dan ekonomi masyarakat yang buruk.

Berdasarkan kondisi di atas relokasi masyarakat diperlukan untuk bisa tinggal di tempat yang lebih baik, baik dari segi lingkungan maupun dari segi kesehatan. Program normalisasi dikawasan bantaran sungai yang berkoordinasi dengan Kementrian Pekerjaan Umum, Pemprov DKI Jakarta berupaya merelokasi warga yang tinggal di pinggiran sungai untuk bisa menempati rumah susun yang akan direncanakan. Berdasarkan informasi yang saya dapatkan, masyarakat kelurahan pondok kelapa Jakarta Timur, yang tinggal di bantaran sungai ciliwung sebanyak 243 KK ( tiga RT ). Untuk mendukung proses normalisasi, pemerintah secara khusus 
menargetkan pembangunan 50.000 unit rusun yang tersebar di wilayah Jakarta Timur, Jakarta Utara, Jakarta Barat, Jakarta Selatan. Dan salah satunya rencana pemerintah dengan pembangunan rusun di Jakarta Timur Pondok Kelapa Village. untuk merelokasikan warga jakarta yang tinggal di bantaran kali ciliwung.

Manusia membangun bangunan demi memenuhi kebutuhannya sendiri, kemudian bangunan itu membentuk perilaku manusia yang hidup dalam bangunan tersebut, namun perilaku juga mempengaruhi sebuah ruang. Hal ini menyangkut kestabilan antara arsitektur dan sosial dimana keduanya hidup berdampingan dalam keselarasan lingkungan.

Dalam hal ini metode Behavior Mapping ( pemetaan perilaku ) sangat cocok untuk mengamati sebuah perilaku masyarakat yang akan di relokasikan ke bangunan rusun agar masyarakat terbiasa dan tidak merasa asing untuk tinggal di bangunan baru yaitu rusun.

Pembangunan rumah susun merupakan salah satu alternatif pemecahan masalah kebutuhan perumahan dan permukiman terutama di daerah perkotaan yang jumlah penduduknya terus meningkat, karena pembangunan rumah susun dapat mengurangi penggunaan tanah, membuat ruang-ruang terbuka kota yang lebih lega dan dapat digunakan sebagai suatu cara untuk peremajaan kota bagi daerah-daerah kumuh. Sehingga dapat membentuk prilaku sosial yang lebih baik.

\section{Tinjauan Pustaka}

Rumah usun adalah bangunan gedung bertingkat yang dibangun dalam suatu lingkungan yang terbagi dalam bagian-bagian yang distrukturkan secara fungsional dalam arah horizontal maupun vertikal dan merupakan satuansatuan yang masing-masing dapat dimiliki dan digunakan secara terpisah, yang berfungsi untuk tempat hunian,yang dilengkapi dengan bagian bersama, benda bersama dan tanah bersama.(Peraturan Mentri Pekerjaan Umum No :05/PRT/M/2007 Tentang Pedoman Teknis Pembangunan Rumah Susun Sederhana Bertingkat Tinggi)

Prasarana dan sarana rumah susun adalah kelengkapan dasar fisik lingkungan yang memungkinkan lingkungan rumah susun dapat berfungsi sebagaimana mestinya, antara lain

\section{METODOLOGI}

Metode pembahasan Behavior Mapping dilakukan dengan menguraikan dan menjelaskan data secara jelas dan terperinci kemudian dianalisa untuk memperoleh suatu kesimpulan. Pengumpulan data diperoleh dengan cara :

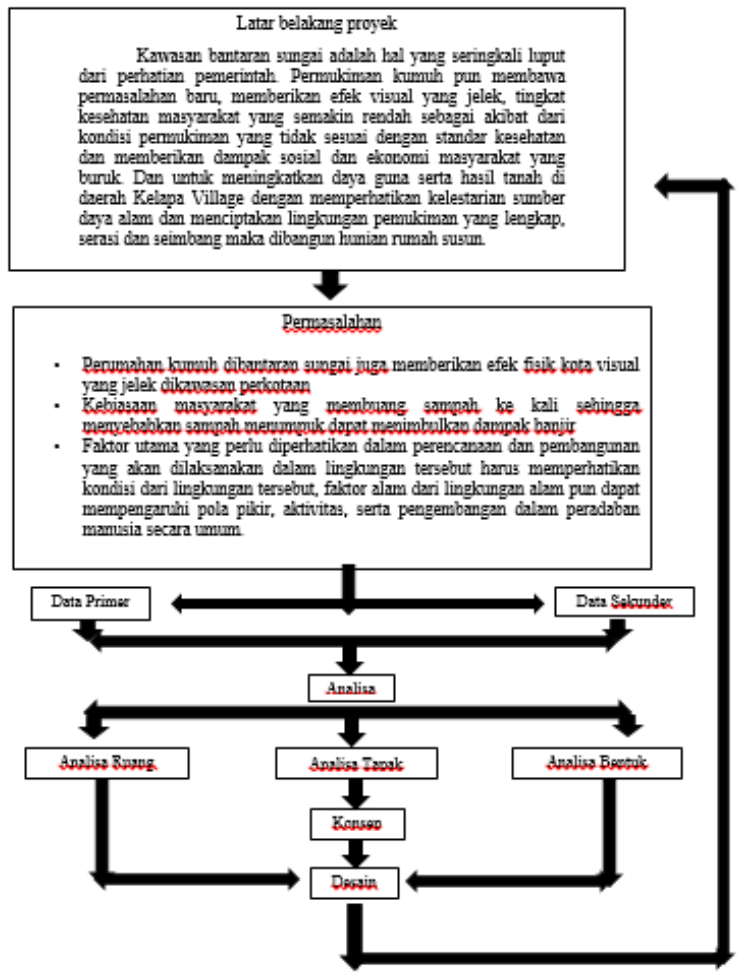

Bagan 1. Alur Proses Perancangan

1. Wawancara

Wawancara dilakukan dengan berbagai pihak yang terkait untuk menggali data yang berkaitan dengan topik.

2. Observasi / survey

3. Observasi lapangan dilakukan dengan mengadakan pengamatan dan pendataan langsung di lokasi.

Proses pada perancangan rumah susun ini yaitu : Pengkumpulan Data

1. Data Primer

a. Data ukuran, bentuk, topografi, kebisingan, vegetasi, potensi tapak.

b. Data fisik: kondisi sarana dan prasarana tapak, lalu lintas dan transportasi sekitar tapak, dan bangunan tapak. 
2. Data Sekunder

a. Studi pustaka atau studi literature yang berkaitan langsung dengan judul dan tema yang dipilih untuk mendapatkan informasi dan bahan berupa literature yang sesuai dengan materi laporan, berguna untuk memperkuat fakta.

b. Studi banding terhadap proyek dan tema sejenis dengan melakukan pendekatan perancangan dengan melihat keadaan yang sudah ada, sumber dapat berupa buku, majalah, maupun internet.

\section{Dokumentasi}
a. Peraturan dan perundangan terkait perancangan
b. Kebutuhan ruang
c. Data tentang arsitektur perilaku

\section{HASIL DAN PEMBAHASAN}

Tapak yang terpilih merupakan hasil analisa data data yang dilakukan oleh penulis, kelapa Vilage di Pondok Kelapa, Jakarta Timur.

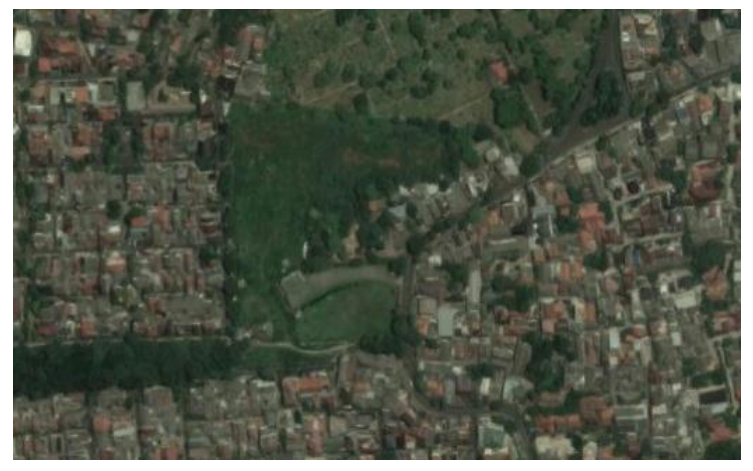

Gambar 1. Lokasi Site

Sumber : Lokasi Kelapa Village

\section{Penzoningan}

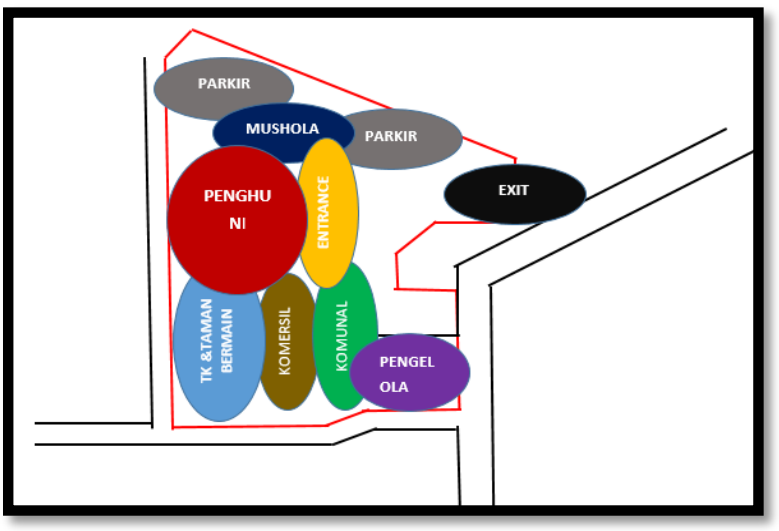

Gambar 2. Zoning

\section{Keterangan :

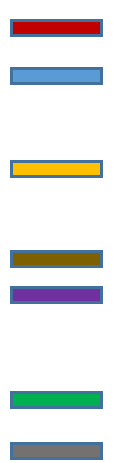 \\ Zona Penghuni \\ Zona Pendidikan Anak dan Taman bermain \\ Zona Tempat penurunan barang atau tamu dan penghuni rusun Zona Toko, Aktivitas jual beli. Zona Pengelolaan, service, keamanan, peralatan. Zona Public, area bersantai, berkumpul bersama tetangga. Zona Parkir}

Untuk analisa kegiatan aktifitas dari masingmasing pelaku, maka dibutuhkan ruang-ruang. Ruang-ruang tersebut terbagi menjadi 4 bagian yaitu zona hunian, zona pengelola dan servis, zona publik dan zona parkir.

a. Zona hunian

Zona hunian merupakan tempat tinggal dari para pengguna rumah susun yang terdiri 2 ruang tidur, (ruang bersama ruang tamu, ruang keluarga), 1 kamar mandi, dan servis seperti (dapur dan cuci jemur)

b. Zona pengelola dan servis

Di dalam pemukiman terdapat ruang pengelola yang bertugas sebagai mengelola kebutuhan rumah susun yang melakukan aktifitas berkerja dari jam 07.00 wib sampai jam 17.00 wib. Pegawai pengelola rumah susun adalah pegawai negri sipil dan Kementrian Pekerjaan Umum. Selain itu masyarakat juga membuat kegiatan pada malam hari menjaga keamanan rusun dengan cara bergantian pada setiap lantai penghuni rusun, dengan kegiatan ini masyarakat lebih sering bersosialisasi sehingga dapat memberikan dampak positif bagi penghuni rumah rusun.

c. Zona kegiatan publik

Zona ini digunakan pengguna rusun sebagai area berkumpul, duduk santai, berbagi informasi, bertamu, dan melakukan aktifitas sosial lainya sehingga, dapat memberikan dapak positif

d. Zona parkir

Zona parkir merupakan tempat menitipkan kendaran berupa kendaraan yang beroda dua maupun beroda empat yang digunakan oleh 
penghuni rusun, pengunjung rusun, dan pengelola rusun.

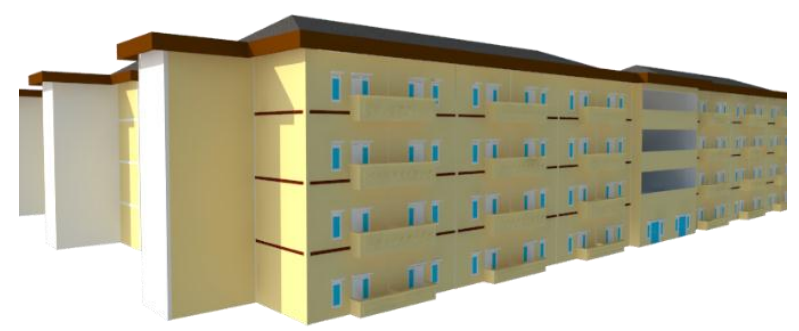

Gambar 3. Fasad Bangunan

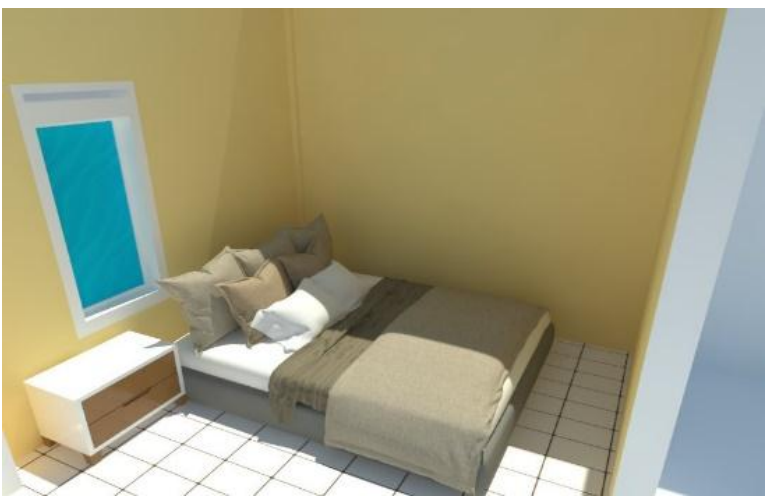

Gambar 4. Interior Kamar

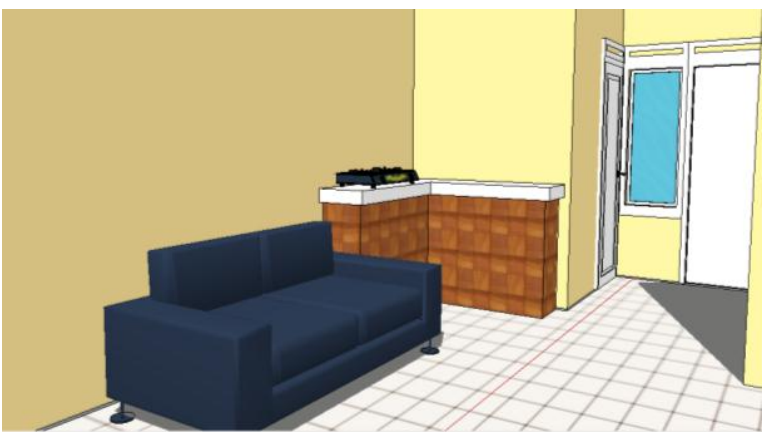

Gambar 5. Interior Ruang Keluarga

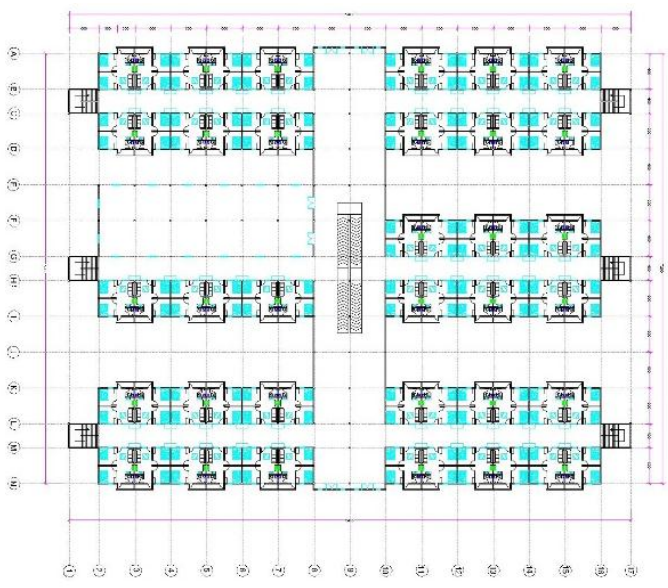

Gambar 6. Denah Rusun

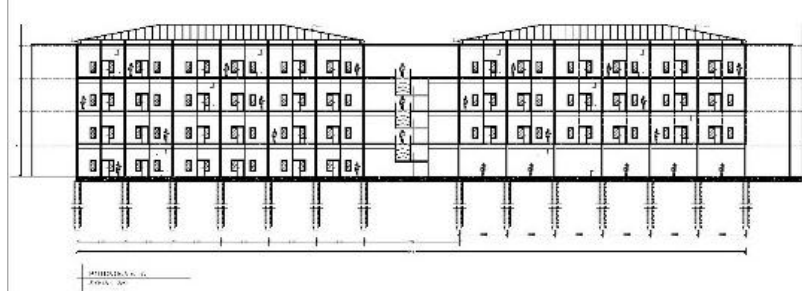

Gambar 7. Potongan AA

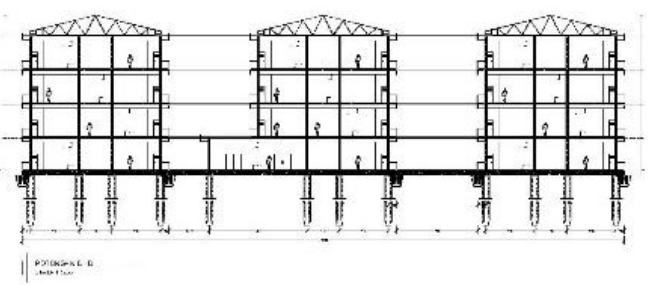

Gambar 8. Potongan BB

\section{PENUTUP}

\section{Simpulan}

Berdasarkan pembahasan mengenai perancangan rumah susun di pondok kelapa Jakarta timur melalui setudy lapangan dan setudy pustaka jadi dapat disimpulkan bahwa

Sebagian masyarakat di Jakarta Timur khususnya kelurahan Pondok Kelapa masih banyak yang tinggal di bantaran sungai, kurang nya kesadaran dari masyarakat sendiri tentang penting nya menjaga kebersihan sungai untuk tidak membuang sampah di sungai menjadikan sungai terlihat kumuh dan banyak tumpukan sampah yang dapat menyebabkan dampak buruk bagi lingkungan sungai itu sendiri., sedangkan dalam UUD No 1 Tahun 2011 tentang perumahan dan kawasan pemukiman bahwa "setiap orang berhak hidup sejahtera lahir dan batin, berempat tinggal dan mendapatkan lingkungan hidup yang baik dan sehat

Berdasarkan data yang saya peroleh dari RTRW pemerintah bahwasannya site Pondok Kelapa di Jakarta tepatnya di jalan H. Naman merupakan wilayah perumahan vertical sehingga saya dapat membuat perancangan rumah susun untuk merelokasikan masyarakat yang tinggal di bataran sungai,dengan adanya rumah susun bagi masyarakat bataran sungai dapat memberi 
pengaruh baik terhadap perkembangan kota seperti memberikan efek visual yang baik dikawasan perkotaan, membuat ruang penghijauan peresapan, sehingga kota tertata rapih dan meningkatkan kesehatan bagi masyarakat

\section{Saran}

Berdasarkan kesimpulan dari hasil pembahasan tentang perencangan rumah susun di pondok kelapa Jakarta timur adapun saran yang dapat dipertimbangkan antaralain :

1. Dalam pembangunan rumah susun lahan untuk fasilitas pembangunan akan lebih efektif apabila lahan tersebut lebih luas sehingga kualitas ruang lebih maksimal dan lebih memadai.

2. Bangunan rumah susun hendaknya memperhatikan budaya masyarakat yang tidak senang terhadap bangunan bertingkat seperti halnya rumah susun, sehingga perlu pendekatan persuasif dan penejelasan detail terhadap keuntungan tinggal dirumah susun dari pada tinggal dipemukiman kumuh.

3. Dan terakhir, penulis tugas akhir perancangan rumah susun Pondok Kelapa Jakarta Timur ini masih jauh dari kata sempurna. Saya sebagai penulis mohon maaf sebesar-besarnya apabila terdapat kesalahan pada penulisan dan perencanaan tugas akhir ini. Semoga tugas akhir ini dapat berguna bagi pembaca dan khalayak umum. Kritik dan saran mengenai penulisan dan perencanaan tugas akhir ini akan sangat berarti. Akhir kata saya mengucapkan terimakasih kepada pembaca dan saya ucapkan selamat membaca.

\section{DAFTAR PUSTAKA}

\section{Buku}

Laurens, Joyce Marcella. 2004.Arsitektur dan Prilaku, Jakarta: Grasindo

Neufert, Ernst. 2002. Data Arsitek: Jilid 1, yang kedua Jakarta: Erlangga

Sumaryoto, Prof. Dr. H. 2015. Panduan Penulisan Skripsi/Tugas Akhir dan Tesis. Jakarta: Unindra Press.

\section{Peraturan Pemerintah}

(Peraturan Mentri Pekerjaan Umum No:05/PRT/M/2007 Tentang Pedoman Teknis Pembangunan Rumah Susun Sederhana Bertingkat Tinggi)

Peraturan mengenai sewamenyewa rumah diatur dalam Pemerintah No.17 Tahun 1963 dan Peraturan Pemerintah No.55 Tahun 1981.

Undang-Undang RI No.20 Tahun 2011 Pengertian Rumah Susun, Rumah Susun Negara, dan Rumah Susun Komersial

Undang-Undang yang mengatur kepemilikan rumah susun diatur dalam undang-undang Rumah Susun No.16 Tahun 1985.

\section{Internet}

http://simplestudio.wordpress.com/2012/12/26/art i-bentuk-dalam-desain/diakses mei 2019 https://www.academia.edu/32691488/BEHAVIO R MAPPINGPEMETAAN PERILAKU DALAM_PENELITIAN_DAN_PERANC ANGAN_ARSITEKTUR

https://ejournal.unsrat.ac.id/index,php/jmm/article /donwload/diunduh 10 juni 2019 